\title{
A Study on coupling Coefficients between adjacent Earth Systems
}

\author{
HITOSHI KIJIMA, \\ Tokaigakuin University
}

\author{
KOJI YOSHIDA \\ NTT \\ JAPAN
}

\author{
CHIKASHI OKABAYASHI \\ Sankosha Corporation
}

\begin{abstract}
This paper proposes a calculation method and a measurement method of coupling coefficients between adjacent earth systems. We consider the different earth systems which are installed nearby. An abnormal current such as a power fault current flowing into one earth system may raise the potential of another earth system and damage the equipment connected to it. For this reason, it is necessary to make the earth potential rise between earth systems more clear. Therefore, we have derived a method for calculating the coupling coefficients between adjacent earth systems composed of complicated electrode arrangement. We applied the current superposition method for the calculation. We also propose two simple and accurate measurement methods of them. As a result of measuring the actual earth systems in the fields, it was confirmed that the calculated values and the measured values are in good agreement.
\end{abstract}

Key-Words: Communication, Earth potential rise, coupling coefficient, electrode, current superposition method

Received: June 23, 2020. Revised: November 5, 2020, Accepted: November 23, 2020. Published: December 3, 2020.

\section{Introduction}

We have investigated EMC technologies as listed in the articles [1]-[3]. One of EMC technologies to be considered is earth systems.

In Fig. 1, when the current $I_{a}$ flows into the earth system $E_{a}$, the earth potential rise of $E_{a}$ becomes $V_{a}=R_{a} I_{a}$. At this time, the earth potential rise $V_{b}$ is generated at the earth system $E_{b}$ installed nearby $E_{a}$. We defined the coupling coefficient $\alpha_{a b}$ between earth system $E_{a}$ and earth system $E_{b}$ as follows.

$$
\alpha_{a b}=V_{b} / V_{a}
$$

If earth system is composed of simple earth electrode, earth potential rise is easily calculated. However in the case of earth systems having many electrodes, earth potential rise becomes too complicated [4]-[12]. Therefore calculation method of the coupling coefficients between adjacent earth systems has not yet been derived.

This paper proposes a calculation method and a measurement method of coupling coefficients between adjacent earth systems. We consider the different earth systems which are installed nearby. An abnormal current such as a power fault current flowing into one earth system may raise the potential of another earth system and damage the equipment connected to it. For this reason, it is necessary to make the earth potential rise between earth systems more clear. Therefore, we have derived a method for calculating the coupling coefficients between adjacent earth systems composed of complicated electrode arrangement. We applied the current superposition method for the calculation[13]. We also propose two simple and accurate measurement methods of them. As a result of measuring the actual earth systems in the fields, it was confirmed that the calculated values and the measured values are in good agreement.

$\rightarrow$ Distance
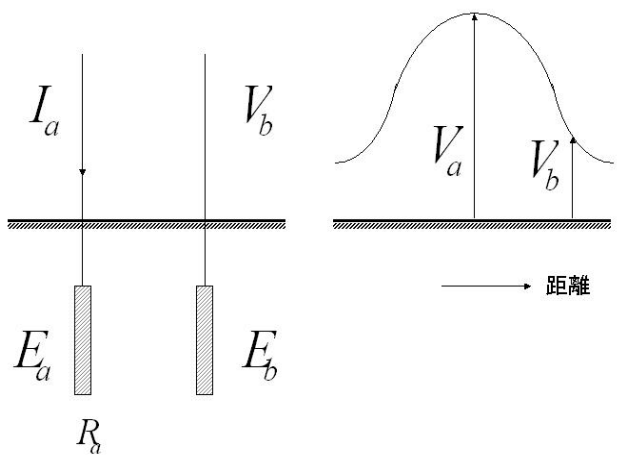

Fig. 1 Definition of coupling coefficient between adjacent earth systems

\section{Proposal of calculation method for coupling coefficient between earths}

We will consider a rod-shaped electrode that is commonly used.

As shown in Fig. 2, the calculation method is shown by taking the case where there are three earth systems 1,2 and 3. The currents flowing through the earth system 1, earth system 2 and earth system 3 are $J_{1}, J_{2}$, and $J_{3}$ respectively. If the number of earth electrodes is $\mathrm{a}, \mathrm{b}$ and c respectively, the total number of earth electrodes $\mathrm{N}$ becomes $\mathrm{N}=\mathrm{a}+\mathrm{b}+\mathrm{c}$. 
In this paper, a uniform line current source having the same length as the electrode is assumed for simplicity. The potential of the electrode is calculated from this current source.

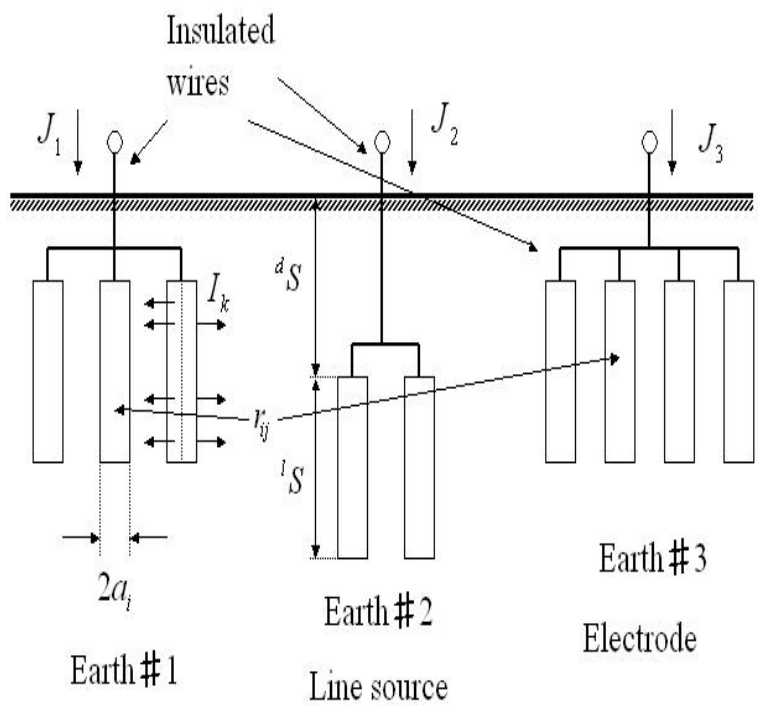

\section{Fig.2 Adjacent earth model used for analyses}

In the case of the earth system 1 , the current of $J_{1}$ is flow split into $J_{1} / a$, in the case of earth system 2 , the current of $J_{2}$ is split into $J_{2} / b$, and in the case of earth system 3, the current of $J_{3}$ is split into $J_{3} /$ c. By these current distributions, each earth electrode potential becomes $V_{i}$. Equation (1) is obtained if the currents are $I_{j}(\mathrm{j}=1,2, \cdot \cdots$, $\mathrm{N})$, and the potentials of the electrode are $V_{i}(\mathrm{i}=1,2, \cdots, \mathrm{N})$.

$$
V=\left[Z_{i j}\right] \text { or } I=\left[Z_{i j}\right]^{-1} V
$$

Where

$$
\begin{aligned}
& V= \\
& {\left[V_{1}, \cdots, V_{a}, V_{a+1}, \cdots, V_{a+b}, V_{a+b+1}, \cdots, V_{a+b+c}\right]} \\
& \quad I= \\
& {\left[I_{1}, \cdots, I_{a}, I_{a+1}, \cdots, I_{a+b}, I_{a+b+1}, \cdots, I_{a+b+c}\right]}
\end{aligned}
$$

Or, if $i \neq j \quad$ becomes

$$
\begin{aligned}
& Z_{i j}= \\
& \frac{1}{4 \pi \sigma l_{j}}\left[\ln \frac{\sqrt{\left(p_{i}+d_{j}+l_{j}\right)^{2}+r_{i j}^{2}}+p_{i}+d_{j}+l_{j}}{\sqrt{\left(p_{i}+d_{j}\right)^{2}+r_{i j}^{2}}+p_{i}+d_{j}}\right. \\
& \left.+\ln \frac{\sqrt{\left(p_{i}-d_{j}\right)^{2}+r_{i j}^{2}}+p_{i}-d_{j}}{\sqrt{\left(p_{i}-d_{j}-l_{j}\right)^{2}+r_{i j}^{2}}+p_{i}-d_{j}-l_{j}}\right]
\end{aligned}
$$

If $i=j$ then $r_{i j}^{2}$ of equation (2) is replaced with $a_{i j}^{2}$. That is in case of $i \neq j$, the observation point of the potential is taken on the electrode axis.

$$
\begin{aligned}
& a_{j}, l_{j}, d_{j}: \text { Radius, length and depth of } \\
& \text { the } j \text { earth electrode } \\
& \text { (distance from the ground } \\
& \text { surface to the electrode } \\
& \text { head). }
\end{aligned}
$$

$\sigma$ : Earth conductivity (constant)

$p_{i}$ : Depth from surface

$$
p_{i}=-d_{j}-l_{j} / 2
$$

$r_{i j}$ : The horizontal distance between the central axis of the $i$ th electrode and the central axis of the $j$ th electrode.

An example of determining the coupling coefficients between adjacent earth systems is shown below. Fig. 2 describes a case where power fault current $J_{1}$ injects only one earth, for example, how much the earth potentials of other adjacent earth system 2 and earth system 3 are calculated. In this case, assuming that the currents of the earth system 2 and earth system 3 are zero, For the potential $\phi_{1}$ of the earth system 1 , the coupling coefficients at which the potential $\phi_{2}$ and the potential $\phi_{3}$ of the earth system 2 and 3 are calculated. That is, as shown in Eq. (3), the current value $J_{1}$ flowing into the earth system 1 is given, and the potentials $\phi_{1}, \phi_{2}$ and $\phi_{3}$ of each earth are obtained as shown in Eq. (4).

$$
\begin{aligned}
& \sum_{j=1}^{a} I_{j}=J_{1} \\
& \sum_{j=a+1}^{a+b} I_{j}=J_{2}=0 \\
& \sum_{j=a+b+c}^{N-a+b+c} I_{j}=J_{3}=0 \\
& V_{1}=V_{2}=, \cdots,=V_{a}=\phi_{1} \\
& V_{a+1}=, \cdots,=V_{a+b}=\phi_{2} \\
& V_{a+b+1}=, \cdots,=V_{a+b+c}=\phi_{3}
\end{aligned}
$$


In Fig. 2, since all the potentials of the electrodes of the earth system 1 are connected, they are equipotential with $V_{1}=V_{2}=, \cdots,=V_{a}=\phi_{1}$. Similarly, the potentials of the electrodes of the earth systems 2 and 3 are equipotential with $\phi_{2}$ and $\phi_{3}$ respectively.

The coupling coefficients between adjacent earth systems are defined by Eq. (5).

$$
\eta_{21}=\phi_{2} / \phi_{1} 、 \eta_{31}=\phi_{3} / \phi_{1}
$$

The definition of the coupling coefficient between earths is the same as the definition in Section 1, but since the number of earth systems has increased to 3 , the coupling coefficient between earths from earth system 1 to earth system 2 is set to $\eta_{21}$, and from earth system 1 to earth system 3 is set to $\eta_{31}$ to avoid confusion.

Divide the matrix of equation (1) into nine sub matrixes as shown in equation (6).

$$
\left[Z_{i j}\right]^{-1}=\left[\begin{array}{lll}
\left\{q_{11}\right\} & \left\{q_{12}\right\} & \left\{q_{13}\right\} \\
\left\{q_{21}\right\} & \left\{q_{22}\right\} & \left\{q_{23}\right\} \\
\left\{q_{31}\right\} & \left\{q_{32}\right\} & \left\{q_{33}\right\}
\end{array}\right]
$$

Substituting Eq. (6) into Eq. (1) and rearranging it using equations (3) and (4) gives equation (7).

$$
\begin{aligned}
& J_{1}=Q_{11} \phi_{1}+Q_{12} \phi_{2}+Q_{13} \phi_{3} \\
& 0=Q_{11} \phi_{1}+Q_{12} \phi_{2}+Q_{13} \phi_{3} \\
& 0=Q_{11} \phi_{1}+Q_{12} \phi_{2}+Q_{13} \phi_{3}
\end{aligned}
$$

Where $Q_{i j}$ is sum of all the elements of sub matrixes $\left\{q_{i j}\right\}$.

From the equation (7), the potentials of $\phi_{1}, \phi_{2}$ and $\phi_{3}$ for each earth, the coupling coefficients between earths can be calculated.

\section{Proposal of a method for measuring the coupling coefficient between earths}

\subsection{Measurement method 1 (method using transmitter and selection level meter)}

The measurement is performed by the measurement circuit shown in Fig. 3 using a transmitter and a selection level meter. In this measurement, KIKUSUI TYPE433 was used as the transmitter and ANDO TYPE2530 was used as the selection level meter. An AC voltage of 1 2 V having $20 \mathrm{~Hz}$ to $1 \mathrm{kHz}$ was applied to the earth electrode $E_{a}$, and a current of 2 20 mA was injected. The reason for using the selection level meter is to eliminate the influence of the other current sources. At $1 \mathrm{kHz}$, the inductance and the capacitance of the lead wire are $0.1 \%$ or less compared to the earth resistance value and can be ignored.

The level difference $L_{d}$ when the selection level meter is switched between $E_{a}$ and $E_{b}$ can be expressed using $V_{a}$ and $V_{b}$ as shown in Fig. 1.

$$
L_{d}=-20 \log _{10} \frac{V_{b}}{V_{a}}
$$

The coupling coefficient $\alpha_{a b}$ between earth systems is obtained as follows.

$$
\begin{gathered}
\alpha_{a b}=\frac{V_{b}}{V_{a}}, \text { from equation (8), it becomes } \\
\alpha_{a b}=10^{\frac{-L_{d}}{20}}
\end{gathered}
$$

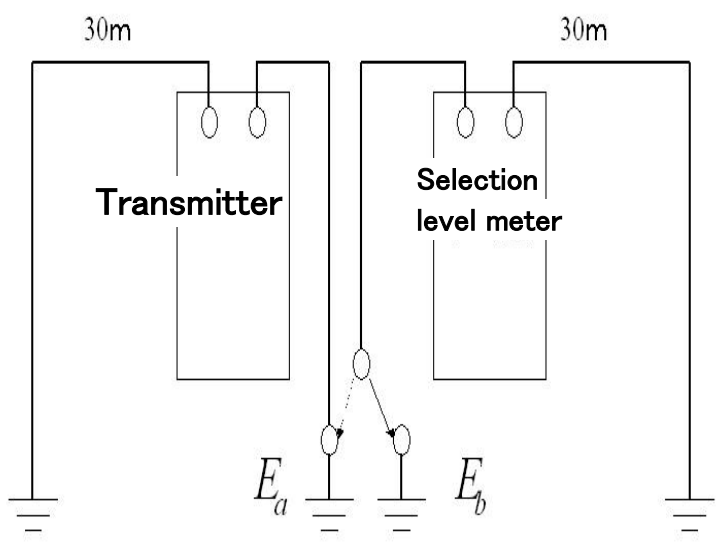

Fig. 3 Method of measuring the coupling coefficient between earths with a transmitter and a selection level meter in combination

\subsection{Measurement method 2 (method using a earth resistance meter) \\ Basic circuit for measuring earth resistance}


value is shown in Fig.4. E is earth electrode to be measured. $\mathrm{C}$ is electrode to return the injecting signal current. $\mathrm{P}$ is potential electrode to provide potential reference point. If $\mathrm{P}$ is far way from $\mathrm{E}$ electrode, this point becomes $0 \mathrm{~V}$. Generally this $0 \mathrm{~V}$ point is located at the middle of E electrode and $\mathrm{C}$ electrode.

The signal frequency of the earth resistance meter differs depending on the measuring instrument, and alternating current of $1 \mathrm{~Hz}$ to $1 \mathrm{kHz}$ is used. In this measurement, Yokogawa TYPE3235 and TYPE3244 were used. In the case of using TYPE3235, a current of 10 30 mA flowed depending on the earth resistance value, and the signal frequency was constant at $500 \mathrm{~Hz}$. On the other hand, in the case of using TYPE3244, a current of 100 300 mA flows depending on the earth resistance value, and the signal frequency was 19 to $24 \mathrm{~Hz}$, which varies slightly depending on the earth resistance value.

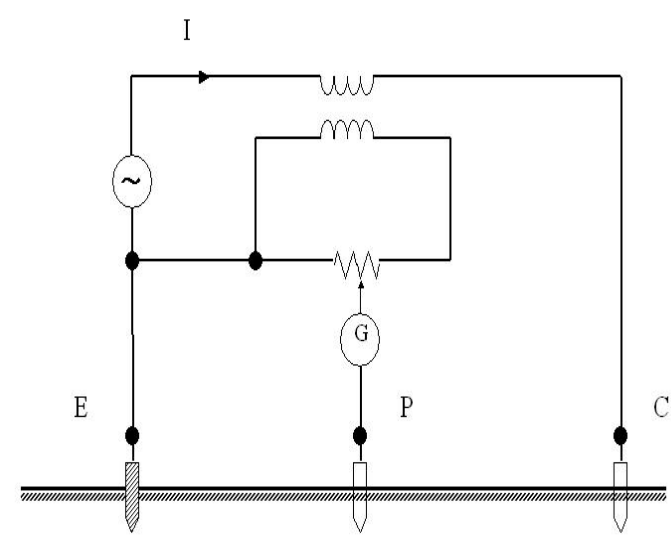

Fig. 4 Basic circuit for measuring earth resistance value

Earth resistance curve is shown in Fig. 5. To obtain the coupling coefficient $\beta$ between $E_{a}$ and $E_{b}, E_{a}$ can be used as E electrode as well as $E_{b}$ can be used as $\mathrm{P}$ electrode.

In this case the coupling coefficient $\beta$ can be obtained as follows.

$$
\beta=\frac{R_{a}-R_{b}}{R_{a}}=\frac{R_{b}^{\prime}}{R_{a}}
$$

Where $R_{a}$ is a true earth resistance value of $E_{a}$ when $\mathrm{P}$ electrode is located far way from $E_{a}$. On the other hand, $R_{b}$ is an earth resistance value of $E_{a}$ when $E_{b}$ is used as $\mathrm{P}$ electrode. This $R_{b}$ is
$R^{\prime}{ }_{b}$ lower than the true earth resistance value of $R_{a}$.

It means that the shaded area in Fig. 5 indicates earth potential rise of $E_{a}$.

In other word, $E_{a}$ is proportional to $R_{a}$, and $E_{b}$ is proportional to $R_{b}^{\prime}$ as follows.

$$
\begin{aligned}
& E_{a}: R_{a}=E_{b}: R_{b}^{\prime} \\
& \beta=E_{b} / E_{a}=R_{b}^{\prime} / R_{a}
\end{aligned}
$$

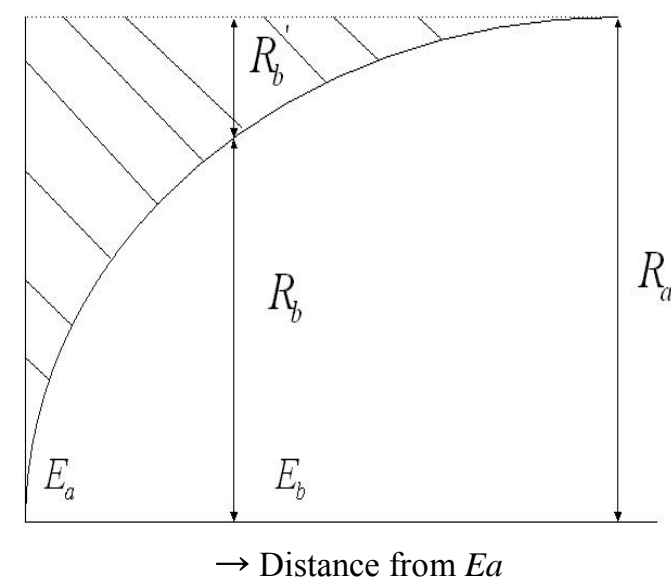

Fig. 5 Earth resistance curve

Therefore, $\beta=\alpha_{a b}$, and the coupling coefficient between earths can be obtained.

\section{Preliminary experiment for measuring the coupling coefficient at laboratory site}

Fig. 6 shows the results of measuring the coupling coefficient between $E_{a}$ and $E_{b}$ at the NTT R\&D Center located in Tokyo using the measurement method 1 and the measurement method 2. Table 1 shows the specifications of the earth electrode.

The earth conductivity at the site is $0.078 \mathrm{~S} /$ $\mathrm{m}$.

Table 1 Specifications of earth electrode

\begin{tabular}{|l|l|}
\hline Specifications \\
\hline Length & $66 \mathrm{~cm}$ \\
\hline Radius & $5 \mathrm{~mm}$ \\
\hline Depth & $65 \mathrm{~cm}$ \\
\hline Material & Iron \\
\hline Plate & Copper \\
\hline
\end{tabular}


From Fig. 6, it can be seen that the measured results by the measurement method 1 and the measurement method 2 are nearly the same.



Fig. 6 Measured results of coupling coefficient between earths

\section{Measured results in the actual fields}

The coupling coefficients between earths were measured in the two different actual fields. The measuring instrument used is Yokogawa TYPE3244 applying the measurement method 2. The specifications of the earth electrode were the same as those listed in Table 1.

\subsection{Measured results at the factory site}

The coupling coefficients between earths were measured at the factory site in Gunma prefecture located $100 \mathrm{~km}$ far way from Tokyo. The earth resistance values are listed in Table 2. The arrangement of the earth electrode is shown in Fig. 7. The earth conductivity at the site is $0.09 \mathrm{~S} / \mathrm{m}$.

Table 2 Earth resistance measured values

\begin{tabular}{|l|l|}
\hline No. & Earth resistance $(\Omega)$ \\
\hline$\# 1$ & 19.0 \\
\hline$\# 2$ & 20.7 \\
\hline$\# 3$ & 21.2 \\
\hline$\# 4$ & 14.8 \\
\hline
\end{tabular}

Table 3 lists the comparison of calculated values and the measured results of the coupling coefficients of between earths.

In Table 3, the calculated values/measured results has a deviation of 53 to $108 \%$. It is probable that this deviation was caused by the local non-uniformity of the earth conductivity in the horizontal and vertical directions at the site, although the earth conductivity was assumed constant in the calculation

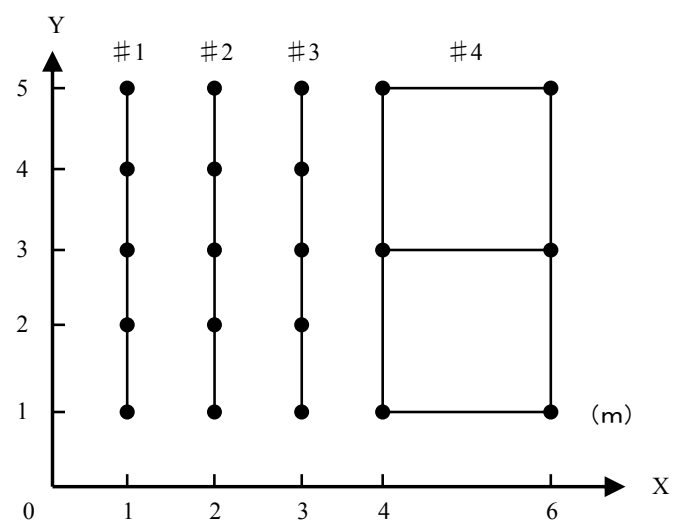

Fig. 7 Arrangement of earth electrodes

Table 3 Comparison of calculated values and measured results of the coupling coefficients between earths

\begin{tabular}{|c|c|c|c|c|}
\hline $\begin{array}{c}\text { Potential } \\
\text { rise } \rightarrow\end{array}$ & & 40 & 110 & \\
\hline $\begin{array}{c}\text { Current } \\
\text { injecting } \\
\downarrow\end{array}$ & & \#2 & +0 & \\
\hline$\# 1$ & & $\begin{array}{l}0.245 \\
0.160\end{array}$ & $\begin{array}{l}0.175 \\
0.098\end{array}$ & $\begin{array}{l}0.114 \\
0.055\end{array}$ \\
\hline$\# 2$ & $\begin{array}{l}0.245 \\
0.148\end{array}$ & & $\begin{array}{l}0.244 \\
0.148\end{array}$ & $\begin{array}{l}0.142 \\
0.068\end{array}$ \\
\hline$\# 3$ & $\begin{array}{l}0.176 \\
0.089\end{array}$ & $\begin{array}{l}0.244 \\
0.145\end{array}$ & & $\begin{array}{l}0.188 \\
0.097\end{array}$ \\
\hline$\# 4$ & $\begin{array}{l}0.140 \\
0.072\end{array}$ & $\begin{array}{l}0.175 \\
0.098\end{array}$ & $\begin{array}{l}0.231 \\
0.131\end{array}$ & \\
\hline
\end{tabular}

Above: Calculated values

Below: Measured results

However, since this degree of deviation is usually observed in the field, it can be said that the calculated values and the measured results are in good agreement. 


\subsection{Measured results at the telephone} office site

The coupling coefficients between earths were measured at the telephone office site in
Gunma prefecture. The earth electrode arrangement is shown in Fig.8. The earth conductivity at the site is $0.3 \mathrm{~S} / \mathrm{m}$.

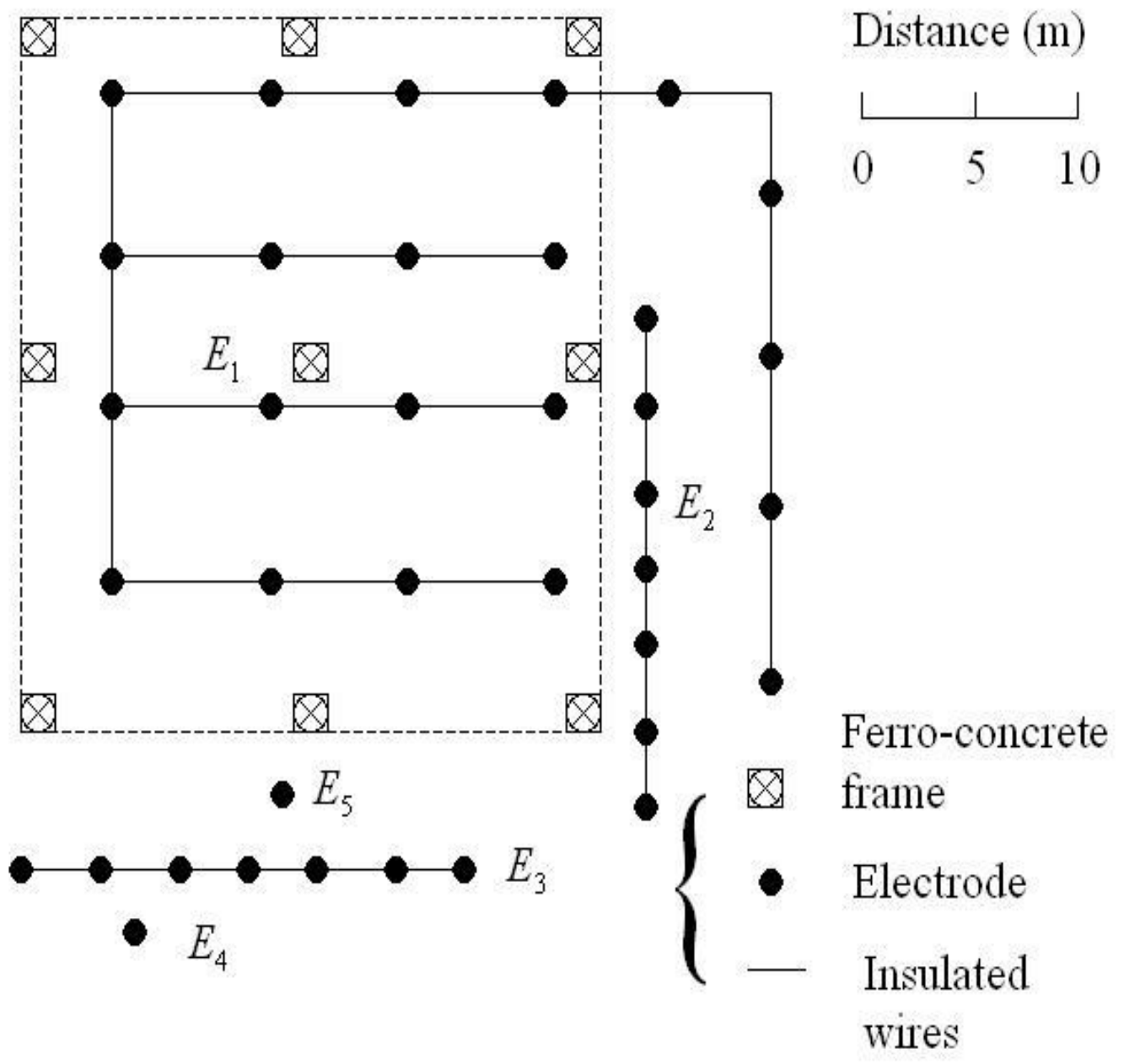

Fig. 8 Arrangement of earth electrodes 
Table 4 lists the comparison of calculated values and measured results of the coupling coefficients between earths. In Table 4, the calculated values/measured results has a deviation of -41 to $+217 \%$. This deviation is slightly larger than the result on the factory site in
Section 5.1, but it is probable that it was caused by the large non-uniformity of the earth conductivity because the site area of the telephone office as large as 1,000 square meters.

Table 4 Comparison of calculated values and measured results of the coupling coefficient between earths

\begin{tabular}{|c|c|c|c|c|c|}
\hline $\begin{array}{c}\text { Current } \\
\text { injecting } \\
\rightarrow \\
\text { Potential } \\
\text { rise } \downarrow\end{array}$ & $E_{1}$ & $E_{2}$ & $E_{3}$ & $E_{4}$ & $E_{5}$ \\
\hline$E_{1}$ & & $\begin{array}{l}0.182 \\
0.152 \\
\end{array}$ & $\begin{array}{l}0.095 \\
0.077 \\
\end{array}$ & $\begin{array}{l}0.017 \\
0.010 \\
\end{array}$ & $\begin{array}{l}0.024 \\
0.010\end{array}$ \\
\hline$E_{2}$ & $\begin{array}{l}0.455 \\
0.533 \\
\end{array}$ & & $\begin{array}{l}0.100 \\
0.072\end{array}$ & $\begin{array}{l}0.017 \\
0.009\end{array}$ & $\begin{array}{l}0.025 \\
0.010\end{array}$ \\
\hline$E_{3}$ & $\begin{array}{l}0.261 \\
0.352 \\
\end{array}$ & $\begin{array}{l}0.110 \\
0.104 \\
\end{array}$ & & $\begin{array}{l}0.058 \\
0.064 \\
\end{array}$ & $\begin{array}{l}0.054 \\
0.017\end{array}$ \\
\hline$E_{4}$ & $\begin{array}{l}0.222 \\
0.352 \\
\end{array}$ & $\begin{array}{l}0.093 \\
0.104\end{array}$ & $\begin{array}{l}0.285 \\
0.483\end{array}$ & & $\begin{array}{l}0.039 \\
0.017\end{array}$ \\
\hline$E_{5}$ & $\begin{array}{l}0.324 \\
0.400 \\
\end{array}$ & $\begin{array}{l}0.131 \\
0.116 \\
\end{array}$ & $\begin{array}{l}0.262 \\
0.123 \\
\end{array}$ & $\begin{array}{l}0.039 \\
0.017 \\
\end{array}$ & \\
\hline
\end{tabular}

Above: Calculated values

Below: Measured results 
However, the coupling coefficients between particularly large earth systems $\left(E_{1}, E_{2}, E_{3}\right)$ are in good agreement by -26 to $+38 \%$. It is considered that the non-uniformity of $E_{1}, E_{2}, E_{3}$ were compensate due to large earth systems. Considering these facts, it can be said that the calculated values and the measured results are in good agreement.

\section{Conclusions}

This paper proposed calculation method and a measurement method of coupling coefficients between adjacent earth systems.

(1) If earth system is composed of simple earth electrode, earth potential rise is easily calculated. However in the case of earth systems having many electrodes, earth potential rise becomes too complicated. Therefore calculation method of coupling coefficients between adjacent earth systems has not yet been derived.

(2) We have derived a method for calculating the coupling coefficients between adjacent earth systems composed of complicated electrode arrangement by applying the current superposition method.

(3) We also proposed two simple and accurate measurement methods. One is to use a transmitter and a selection level meter in combination, and the other is to apply the measurement principle of the earth resistance meter.

(4) As a result of measuring the actual earth systems in the fields, it was confirmed that the calculated values and the measured results are in good agreement.

\section{References:}

[1]C.Okabayashi, H. Kijima, Lightning Protection for Mobile Phone Base Stations by combining $\lambda / 4$ short Stub and $\lambda / 4$ open Stub , WSEAS Transactions on communications, Vol.19, pp.249-255, 2020 [2]H. Kijima, C.Okabayashi, Newly developed compact isolation transformers for signaling networks, WSEAS Transactions on communications, Vol.19, pp.179-186, 2020

[3]H. Kijima, The current and magnetic field distribution generated by direct lightning strikes on buildings using FEM analysis, Engineering World, Vol.2, pp.120-127, 2020

[4] Erath resistance and measurement practice, EPR magazine editorial, 2020

[5] Measurements and calculations of earth electrodes systems, electrical engineering portal, 2018

[6] IEEE standard 81-2012, Standard for earth resistance measurement, 2012

[7] G.F.Tagg: Earth Resistance, London George Newton's Limited, 1964

[8]T.Katayama, Research on the grounding characteristic of the electrode constructed by the perpendicular dislocation ground, Institute of Electrical Installation Engineers of Japan, 2006

[9] T.Makita, H.Suzuki, Grounding property of mesh electrode buried near vertical fault, Nihon University, Report-of-research Vol.39, No.2 pp21-27, 2006 
[10]K.Murakawa, H.Kijima, Earth resistance tester developed using resonant circuit technology with no auxiliary electrode, WSEAS Transactions on communications, Vol.13 pp. 484-493, 2014 [11]H. Kijima, A development of earth resistance estimation instrument, International Journal of geology, Issue 4, vol. 3, pp112-116, 2009

[12]H. Kijima, Earth system and lightning protection, Corona Co. published, ISBN978-4-88552-147-8, fifth print, 2010

[13] Takashima, Nakae, Ishibashi "Electric field calculation method for conductive multi-medium field (current superposition method)" Institute of Electrical Engineers of Japan (A) 100 A, 5 pp259-263, 1978

\section{Creative Commons Attribution License 4.0} (Attribution 4.0 International, CC BY 4.0)

This article is published under the terms of the Creative Commons Attribution License 4.0

https://creativecommons.org/licenses/by/4.0/deed.en_US 